\title{
Structure, process, and outcomes of care in a telemonitoring program for patients with type 2 diabetes
}

\author{
Jill M Nocella' \\ Victoria Vaughan Dickson ${ }^{2}$ \\ Charles M Cleland ${ }^{2}$ \\ Gail D’Eramo Melkus² \\ 'Department of Nursing, William \\ Paterson University, Wayne, NJ, \\ ${ }^{2}$ College of Nursing, New York \\ University, New York, NY, USA
}

This article was published in the following Dove Press journal:

Patient Related Outcome Measures

I March 2016

Number of times this article has been viewed
Background: Using Donabedian's structure-process-outcomes (SPO) framework, this descriptive, exploratory study examined the structure of a telemonitoring program in a population of patients with type 2 diabetes (T2D), the process of nurse-patient telephonic interactions, and patients' clinical outcomes.

Methods: Secondary data analysis was conducted using data from 581 patients who participated in a home telemonitoring program for 12 months. Three point-biserial and six Pearson correlations were estimated to determine how patient demographics related to clinical characteristics. Mixed model regressions were conducted predicting hemoglobin $\mathrm{A}_{1 \mathrm{c}}\left(\mathrm{HbA}_{1 \mathrm{c}}\right)$, systolic blood pressure (SBP), and diastolic blood pressure (DBP) levels at 6, 9, and 12 months based on the frequency of contact in the earlier 3 months. Analysis of variances were conducted to assess if the frequency of contact was significantly different by change in $\mathrm{HbA}_{1 \mathrm{c}}$ levels from 3 to 6,6 to 9 , and 9 to 12 months.

Results: Significant negative correlations were found between age and $\mathrm{HbA}_{1 \mathrm{c}}(r=-0.10, P=0.015)$ and DBP ( $r=-0.16, P<0.001$ ), a significant positive correlation was found between age and $\operatorname{SBP}(r=0.15, P=0.001)$. A significant correlation was found between sex and DBP $\left(r_{\mathrm{pb}}=-0.11\right.$, $P=0.015$ ); female participants had lower DBP levels than males. Frequency of contact was not related to the change in clinical outcomes. However, the frequency of contact for the time period 3 to 6 months was associated with change in $\mathrm{HbA}_{1 \mathrm{c}}$ for the 6- to 9- month period and frequency of contact during the 6- to 9- month period was associated with change in $\mathrm{HbA}_{1 \mathrm{c}}$ from 9 to 12 months.

Conclusion: Examination of the SPO measures in the telemonitoring environment assisted in understanding the effectiveness of this type of unique intervention and the need for further in-depth exploration of self-management techniques among individuals with T2D.

Keywords: telemonitoring, type 2 diabetes, telephonic care, telehealth, telecare

\section{Introduction}

One of the most prevalent of all chronic disease states in the US, type 2 diabetes (T2D) has been diagnosed in 21 million individuals, with an estimated 8.1 million more unaware they have the disease. ${ }^{1}$ Self-management has been identified as a crucial aspect of controlling T2D, as the most important self-care choices affecting the health and the well-being of the individual are made day-to-day and not in the physician's office. ${ }^{2}$ Findings from large-scale clinical trials and systematic reviews of diabetes self-management interventions have identified the need to focus more closely on understanding the effectiveness of nursing interventions on sustained self-management outcomes for individuals with T2D. ${ }^{3,4}$ Research has shown one-size-fits-all approaches
Correspondence: jill M Nocella Department of Nursing, William Paterson University, 300 Pompton Road, 207 Hunziker Wing, Wayne, NJ 07470, USA Email nocellaj I@wpunj.edu 
to diabetes self-management interventions may not always be effective, especially when one considers emerging disparities in diabetes morbidity and mortality ${ }^{5-8}$ The need to understand not only the clinical and utilization outcomes as a result of self-management of T2D but also the processes of care that may contribute to improved outcomes is essential to improving the quality of care provided.

To date, research examining the effectiveness of interventions to support patients' self-management of T2D has included a variety of health care settings across the health care continuum. Within the larger context of diabetes selfmanagement, the use of telemonitoring technology that strongly supports the shift in point of care service from provider-centered to patient-centered and from hospital-based to community-based is noteworthy. ${ }^{9}$ Despite the speed at which telemonitoring technology has advanced and the noted positive clinical and utilization outcomes it has demonstrated in patients with chronic conditions, ${ }^{10-14}$ the research has not focused on the processes of care, which may contribute to improved clinical outcomes. ${ }^{15}$ Further, while telemonitoring has been regarded as an innovative tool to help increase access to care for patients, the focus has not consistently been on its use to sustain clinical outcomes over time. ${ }^{16}$

In light of the current state of the science of diabetes selfmanagement, examining factors that contribute to clinical outcomes in individuals with T2D is needed. Specifically, this study examined the structure and processes of care in a telemonitoring program for managed care recipients and the role that health care providers play in relation to selfmanagement outcomes in patients with T2D.

The specific aims of this study were:

1. To determine how patient demographics is related to clinical characteristics at baseline among patients with T2D participating in the telemonitoring program (structure of care).

2. To determine the association of frequency of contact with a nurse (process of care) and clinical outcomes over time (outcome of care) in patients with T2D participating in the telemonitoring program.

\section{Methods}

Due to the importance of understanding the associations that exist between the structures of care, the processes of care, and the outcomes of care in this home telemonitoring program, the exploratory design was selected. Donabedian's structure-process-outcomes mode ${ }^{17}$ defines structural, process, and outcome measures of quality and further asserts that the three are not independent but are related to one another in an underlying framework whereby good structure should yield good process, and good process should yield good outcomes. ${ }^{18}$

Structural measures are noted to be the professional and organizational resources linked with the provision of care, such as the operating capacities and staff credentials. For the purposes of this study, the operational definition of structure is noted to be the telehealth monitoring system, inclusive of patients, nurses, and physicians, within the larger context of the integrated health care delivery system. Structural measures were operationalized to be the available individual patient demographics of those enrolled in the home telemonitroing program. Process measures of quality are defined as the actions done to and for the patient by nurses and physicians in the course of treatment. ${ }^{19}$ Frequency of contact, whether nurse-initiated or patient-initiated was noted to be the process of care measure that was examined within this study. Finally, Donabedian ${ }^{17}$ defined outcome measures as the desired or intended states resulting from care processes. The clinical outcomes of hemoglobin $A_{1 c}$ $\left(\mathrm{HbA}_{1 \mathrm{c}}\right)$, systolic blood pressure (SBP), and diastolic blood pressure (DBP) from baseline through 12 months, as measured in 3-month time periods, were the outcome measures.

The study was a secondary data analysis conducted using data collected through a preexisting telemonitoring program offered through a large integrated health care delivery system with its own 420,000 member health plan. The health care system provides medical, mental health, and substance abuse services through its eleven acute care hospitals, four skilled nursing facilities, six diagnostic treatment centers, and 70 community-based clinics throughout a large metropolitan area in the Northeast US. The telemonitoring program began enrolling patients in October 2006 with a focus on patients with T2D, identified by individual physicians, who could potentially benefit from the use of a home monitoring device. Eligibility requirements included: written consent from the patient to participate; 18 years of age or older; a permanent address with a working land telephone line; a physician who was willing to participate in the program and who agreed to provide physician orders for program participation; a covered member with medical insurance offered through the managed care company that was contracted with the health care system; an established diagnosis of diabetes with a history of need for frequent health care intervention including increased incidence of emergency room visits, readmission to hospital or agency for skilled care, and/or frequent unscheduled visits to the physician's office or clinic.

With the patient's consent, a telemonitoring device was installed in the patient's home that was capable of transmitting 
daily blood glucose and blood pressure values to a team of six registered nurses via secure high bandwidth transmission. The $\mathrm{HbA}_{1 \mathrm{c}}$ values were available to the registered nurses through a central health care system database. The nurses utilized an alert parameter system that indicated what clinical values to act upon via a call to the patient and, when necessary, consultation with the referring physician. Specifically, each patient's physician established clinical guidelines for triage alerts and care goals, which were reviewed by the nurse and discussed with the patient. Patients were advised that the nurse would respond within 2 hours to any red alert and within 8 hours to any yellow alert that is transmitted. Red alerts were established as greater than $20 \%$ above or below pre-established parameters for blood glucose and blood pressure. Yellow alerts were established as readings outside of the target range, but not within the red alert range. Default settings were put in place for patients whose physicians did not request specific ranges (Figure 1).

This study was submitted and approved by New York University's Committee on Activities Involving Human Subjects (UCAIHS) as well as submitted and approved by the Biomedical Research Alliance of New York (BRANY). As this study was a secondary data analysis of an existing telemonitoring program (where the patients' provided written consent to be part of the program and to have their de-identified data utilized for research purposes), a separate consent was not required to be obtained for this study. The target population was patients with T2D who were enrolled in the telemonitoring program between the dates of January 1, 2008 and December 31, 2010. The data file of patients included 605 actively monitored patients within this time frame, however, due to lack of complete baseline clinical data only 581 patients were included in the study sample. Baseline data collected and available for review included the date of enrollment, date of disenrollment, sex, date of birth, primary language, baseline $\mathrm{HbA}_{1 \mathrm{c}}$, and baseline SBP and DBP. The baseline $\mathrm{HbA}_{1 \mathrm{c}}$, baseline SBP and baseline DBP readings were the first reading that existed on the patient's record in the telemonitoring system. The data collected on an ongoing basis included $\mathrm{HbA}_{1 \mathrm{c}}$, SBP and DBP, months enrolled in the program, and contact history including frequency of contact. At 3 months from the initial enrollment date, the 3 month blood pressure reading that existed in the telemonitoring system was obtained in systolic/diastolic format. These data were provided at the 6 , 9 , and 12 months time frame for each patient from the date of his or her enrollment in the program through December 31, 2010. While the $\mathrm{HbA}_{1 \mathrm{c}}$ represented a measure of blood glucose control over each 3-month time frame, the blood pressure readings collected were point-in-time and did not represent an average over time.

The researcher did not have access to individual patient medical history, comorbid conditions, medication regime, prescribed diet, or activity levels. The researcher did have access to the individual patient's inpatient and emergency room visits that occurred during the 12 months for which the patient was part of the home telemonitoring program. Examination and analysis of patient utilization outcomes were not within the scope of the current study.

\section{Data analysis}

The principal analysis phase involved testing each of the two hypotheses related to this study. To assess the first study aim, to determine how patient demographics related to baseline clinical characteristics, three point-biserial and six Pearson correlations were estimated. Prior to addressing the second study aim, to determine if the frequency of contact with a nurse was associated with a change in clinical outcomes $\left(\mathrm{HbA}_{1 \mathrm{c}}, \mathrm{SBP}\right.$, and DBP), nine multiple linear regressions were conducted as a sensitivity test. This was done to assess if the frequency of contact predicted the clinical outcomes after controlling for age, days enrolled, and clinical outcomes 3 months earlier. Three mixed model regressions were then conducted to predict $\mathrm{HbA}_{1 \mathrm{c}}, \mathrm{SBP}$, and DBP levels at 6, 9, and 12 months. Finally, to determine if the frequency of contact with a nurse was associated with a change in $\mathrm{HbA}_{1 \mathrm{c}}$ level in patients participating in the program, analysis of variances (ANOVAs) were conducted.

\begin{tabular}{|l|c|c|c|}
\hline & Target range & Red alert & Yellow alert \\
\hline Blood glucose $(\mathrm{mg} / \mathrm{dL})$ & $76-120$ & $<70$ or $>300$ & $71-75$ or $121-299$ \\
\hline Systolic blood pressure $(\mathrm{mmHg})$ & $97-130$ & $<90$ or $>180$ & $91-96$ or $131-179$ \\
\hline Diastolic blood pressure $(\mathrm{mmHg})$ & $60-80$ & $<50$ or $>100$ & $51-59$ or $81-99$ \\
\hline
\end{tabular}

Figure I Target ranges and alert limits for daily readings. 
The frequency of contact was measured as the number of contacts from baseline to 3 months (time 1), from 3 to 6 months (time 2), and from 6 to 9 months (time 3). $\mathrm{HbA}_{1 \mathrm{c}}, \mathrm{SBP}$, and DBP were measured as the difference between 3 and 6 months (time 1), the difference between 6 and 9 months (time 2), and the difference between 9 and 12 months (time 3). Because the frequency of contact variable was skewed heavily to the right, a natural $\log$ transformation was taken on the frequency of contact after adding the constant 1 . It was hypothesized that the frequency of contact would lead to better patient outcomes of decreased $\mathrm{HbA}_{1 \mathrm{c}}$ levels, SBP, and DBP values in the subsequent 3-month period. This "look back" at the frequency of contact was utilized as a means to determine if the intervention was effective in improving clinical outcomes.

Three mixed model regressions were conducted to assess the relationship between the frequency of contact and $\mathrm{HbA}_{1 \mathrm{c}}$, SBP, and DBP levels. Because the frequency of contact depended on the length of time the participant was enrolled, the number of months enrolled was controlled for. Since age was related to $\mathrm{HbA}_{1 \mathrm{c}}$, DBP, and SBP levels at baseline, age was also controlled for. The frequency of contact was tested as a random factor. However, in all three models, the frequency of contact was not a significant random effect and thus the random effect was not included in the model. A random intercept was included in the model. All the fixed factors in the model were centered at their means.

Three ANOVAs were conducted to assess if the frequency of contact was significantly different by a change in $\mathrm{HbA}_{1 \mathrm{c}}$ levels from 3 to 6,6 to 9 , and 9 to 12 months. The change in $\mathrm{HbA}_{1 \mathrm{c}}$ levels over 3 month intervals were categorized as an increase (those patients who had an increase in $\mathrm{HbA}_{1 \mathrm{c}}$ level from one time period to the next time period), decrease (those patients who had a decrease in $\mathrm{HbA}_{1 \mathrm{c}}$ level from one time period to the next time period), no change-normal (those patients who had a $\mathrm{HbA}_{1 \mathrm{c}}$ level in the normal range of $7 \%$ or less and remained in that normal range for the subsequent time period), no change-near normal (those patients who had a $\mathrm{HbA}_{1 \mathrm{c}}$ level in the near normal range of $7 \%-8 \%$ and remained in that near normal range for the subsequent time period), and no change-poor (those patients who had a $\mathrm{HbA}_{1 \mathrm{c}}$ level in the poor range of $8 \%$ or greater and remained in that poor range for the subsequent time period).

As with the mixed model regressions, the time points were lagged by 3 months, so the change in frequency of contact from baseline to 3 months was assessed in relation to the change in $\mathrm{HbA}_{1 \mathrm{c}}$ from 3 to 6 months. The natural $\log$ transformation was still used for the frequency of contact.

\section{Results}

Five hundred and eighty-one participants comprised the study sample. The majority of the participants was female, spoke English, and was between 51 and 65 years old (Table 1). Frequency of contact was calculated at 3-, 6-, 9-, and 12-month intervals. The total number of months enrolled in the program ranged from 1 to 49 with the average being 17 months (Table 2). $\mathrm{HbA}_{1 \mathrm{c}}$, DBP, and SBP values were taken at baseline, 3-, 6-, 9-, and 12-month time periods. The highest average $\mathrm{HbA}_{1 \mathrm{c}}$, DBP, and SBP levels were at baseline and the lowest average $\mathrm{HbA}_{1 \mathrm{c}}$, DBP, and SBP levels were at 12 months (Table 3 ).

Significant negative correlations were found between age and $\mathrm{HbA}_{1 \mathrm{c}}(r=-0.10, P=0.015)$ and DBP $(r=-0.16$, $P<0.001)$, and a significant positive correlation was found between age and SBP $(r=0.15, P=0.001)$. As age increases, $\mathrm{HbA}_{1 \mathrm{c}}$ level and DBP tended to decrease while SBP tended to increase. There was also a significant correlation with sex and DBP $\left(r_{\mathrm{pb}}=-0.11, P=0.015\right)$ indicating that female participants tended to have lower DBP levels than males.

The results of the sensitivity regressions predicting $\mathrm{HbA}_{1 \mathrm{c}}$ levels showed that the frequency of contact at 6 months predicted $\mathrm{HbA}_{1 \mathrm{c}}$ levels at 9 months. As the frequency of contact increased, $\mathrm{HbA}_{1 \mathrm{c}}$ levels also tended to increase (Table 4). The regressions predicting DBP did not show any significance for the frequency of contact (Table 5). The results of the regressions predicting SBP showed significance in the frequency of contact at 3 months predicting SBP at 6 months. As the frequency of contact increased, SBP levels also tended to increase (Table 6).

Table I Structure of care: frequencies and percentages for demographics of sex, language, and age

\begin{tabular}{lll}
\hline Demographic & $\mathbf{N}=\mathbf{5 8} \mathbf{I}$ & $\%$ \\
\hline Sex & & \\
Female & 382 & 66 \\
Male & 198 & 34 \\
Unknown & $\mathrm{I}$ & \\
Language & & \\
English & 362 & 62 \\
Spanish & 178 & 31 \\
Unknown & 24 & 4.1 \\
Bengali & 10 & 1.7 \\
Creole & 4 & 0.6 \\
Arabic & 3 & 0.5 \\
Age (years) & & \\
I8-35 & 28 & 5 \\
36-50 & 169 & 29 \\
5 I-65 & 342 & 59 \\
66-85 & 42 & 7 \\
\hline
\end{tabular}


Table 2 Process of care: mean and SD for frequency of contact and months enrolled

\begin{tabular}{|c|c|c|c|c|c|c|}
\hline Variable & $\mathbf{M}$ & SD & Median & Minimum & Maximum & Interquartile range \\
\hline Frequency of contact at 3 months & 29.80 & 25.97 & 21 & I & 282 & 17.00 \\
\hline Frequency of contact at 6 months & 49.07 & 38.18 & 37 & I & 309 & 30.00 \\
\hline Frequency of contact at 9 months & 65.18 & 49.55 & 50 & 1 & 335 & 43.25 \\
\hline Frequency of contact at 12 months & 79.00 & 61.38 & 64 & I & 411 & 53.25 \\
\hline Months enrolled & 17.56 & 12.79 & 14.48 & 1.47 & 48.97 & 19.34 \\
\hline
\end{tabular}

Abbreviations: $M$, mean; SD, standard deviation.

Mixed model regressions showed that the frequency of contact was not related to the change in $\mathrm{HbA}_{1 \mathrm{c}}$, DBP, and SBP levels. Results are presented in Table 7.

In ANOVA (Table 8), the frequency of contact from baseline to 3 months was not related to changes in $\mathrm{HbA}_{1 \mathrm{c}}$ levels from 3 to 6 months, $F(4,565)=1.74, P=0.139$. The frequency of contact from 3 to 6 months was related to change in $\mathrm{HbA}_{1 \mathrm{c}}$ levels from 6 to 9 months, $F(4,448)=2.69, P=0.031$. Tukey post hoc testing showed those with a decrease in level had significantly lower frequency of contact compared to those who increased or no change-poor for their change in $\mathrm{HbA}_{1 \mathrm{c}}$ (Table 9). The frequency of contact from 6 to 9 months was related to change in $\mathrm{HbA}_{1 \mathrm{c}}$ levels from 9 to 12 months, $F(4,431)=3.49, P=0.008$. Further testing showed that those who had no change-poor had significantly higher frequency of contact compared to those with no change-normal.

\section{Discussion}

The current study makes a number of important contributions to the current literature on telemonitoring programs for patients with T2D. Within the structure of care measurable variables of the telemonitoring program, patient demographics of age, and $\mathrm{HbA}_{1 \mathrm{c}}$ and DBP were found to be negatively correlated, while age and SBP were found to be positively correlated. Female participants tended to have lower DBP levels than males.

Within the process of care and outcomes of care measurable variables, mixed model regressions revealed that the frequency of contact was not related to changes in $\mathrm{HbA}_{1 \mathrm{c}}$, DBP, and SBP levels. ANOVA showed the frequency of contact from 3 to 6 months was related to change in $\mathrm{HbA}_{1 \mathrm{c}}$ from 6 to 9 months; notably, those patients who had a decrease in $\mathrm{HbA}_{1 \mathrm{c}}$ had fewer contacts than those who had an increase in $\mathrm{HbA}_{1 \mathrm{c}}$ or who had consistent, poorly controlled $\mathrm{HbA}_{1 \mathrm{c}}$. Similarly, the frequency of contact from 6 to 9 months was related to change in $\mathrm{HbA}_{1 \mathrm{c}}$ from 9 to 12 months; notably, those patients who had consistent, poorly controlled $\mathrm{HbA}_{1 \mathrm{c}}$ had more contacts than those who had consistent, well controlled $\mathrm{HbA}_{1 \mathrm{c}}$.

This study provides support for the effectiveness of utilizing a model such as Donabedian's structure-process-outcomes mode ${ }^{17}$ to guide the examination

Table 3 Outcomes of care: mean and SD for $\mathrm{HbA}_{\mathrm{Ic}}$ and systolic and diastolic blood pressures

\begin{tabular}{|c|c|c|c|c|c|c|}
\hline Variable & $\mathbf{M}$ & SD & Median & Minimum & Maximum & Interquartile range \\
\hline \multicolumn{7}{|l|}{$\mathrm{HbA}_{\mathrm{Ic}} \%$} \\
\hline Baseline & 9.76 & 2.17 & 9.30 & 5.40 & 18.20 & 2.73 \\
\hline 3 months & 9.59 & 2.01 & 9.20 & 5.40 & 18.20 & 2.40 \\
\hline 6 months & 8.44 & 1.74 & 8.00 & 5.40 & 16.80 & 1.90 \\
\hline 9 months & 8.22 & 1.57 & 7.90 & 5.00 & 14.00 & 2.18 \\
\hline 12 months & 8.11 & 1.41 & 7.83 & 5.60 & 16.20 & 1.88 \\
\hline \multicolumn{7}{|l|}{ DBP value } \\
\hline Baseline & 80.43 & 10.47 & 80.00 & 44.00 & 129.00 & 12.00 \\
\hline 3 months & 78.58 & 10.38 & 78.00 & 49.00 & 115.00 & 13.00 \\
\hline 6 months & 78.53 & 10.61 & 78.00 & 50.00 & 117.00 & 13.25 \\
\hline 9 months & 77.63 & 10.04 & 77.00 & 48.00 & 121.00 & 12.75 \\
\hline 12 months & 77.57 & 9.96 & 77.00 & 53.00 & 133.00 & 11.00 \\
\hline \multicolumn{7}{|l|}{ SBP value } \\
\hline Baseline & 133.98 & 16.31 & 133.00 & 92.00 & 183.00 & 20.00 \\
\hline 3 months & 132.49 & 16.15 & 132.00 & 84.00 & 183.00 & 23.50 \\
\hline 6 months & 132.09 & 15.72 & 130.00 & 96.00 & 179.00 & 19.25 \\
\hline 9 months & 131.67 & 15.42 & 130.00 & 82.00 & 184.00 & 21.00 \\
\hline 12 months & 130.99 & 15.54 & 129.00 & 101.00 & 192.00 & 19.00 \\
\hline
\end{tabular}

Abbreviations: DBP, diastolic blood pressure; $\mathrm{HbA}_{1 \mathrm{c}}$, hemoglobin $\mathrm{A}_{\mathrm{Ic}}$; $\mathrm{M}$, mean; SBP, systolic blood pressure; SD, standard deviation. 
Table 4 Outcomes of care: sensitivity regressions with frequency of contact predicting $\mathrm{HbA}_{\mathrm{Ic}}$ levels controlling for age, months enrolled, and $\mathrm{HbA}_{\mathrm{Ic}}$ levels 3 months prior

\begin{tabular}{|c|c|c|c|c|c|c|}
\hline Dependent variable & Independent variable & B & SE B & $\beta$ & $\boldsymbol{t}$ & $P$ \\
\hline \multirow{5}{*}{$\mathrm{HbA}_{\mathrm{Ic}}$ at 6 months } & Constant & 3.44 & 0.72 & & 4.76 & 0.001 \\
\hline & $\mathrm{HbA}_{\mathrm{lc}}$ at 3 months & 0.51 & 0.04 & 0.59 & 13.28 & 0.001 \\
\hline & Age (years) & 0.00 & 0.01 & -0.02 & -0.44 & 0.659 \\
\hline & Months enrolled & 0.00 & 0.00 & -0.02 & -0.42 & 0.672 \\
\hline & Frequency of contact at 3 months* & 0.13 & 0.11 & 0.05 & 1.15 & 0.252 \\
\hline \multirow[t]{5}{*}{$\mathrm{HbA}_{\mathrm{Ic}}$ at 9 months } & Constant & 2.12 & 0.79 & & 2.68 & 0.008 \\
\hline & $\mathrm{HbA}_{\mathrm{Ic}}$ at 6 months & 0.47 & 0.04 & 0.60 & 10.74 & 0.001 \\
\hline & Age (years) & 0.00 & 0.01 & 0.03 & 0.51 & 0.612 \\
\hline & Months enrolled & 0.00 & 0.00 & 0.06 & 1.12 & 0.263 \\
\hline & Frequency of contact at 6 months* & 0.38 & 0.11 & 0.20 & 3.45 & 0.001 \\
\hline \multirow[t]{5}{*}{$\mathrm{HbA}_{\mathrm{Ic}}$ at 12 months } & Constant & 2.43 & 0.51 & & 4.76 & 0.001 \\
\hline & $\mathrm{HbA}_{\mathrm{Ic}}$ at 9 months & 0.69 & 0.03 & 0.77 & 20.24 & 0.001 \\
\hline & Age (years) & -0.01 & 0.01 & -0.04 & -0.95 & 0.345 \\
\hline & Months enrolled & 0.00 & 0.00 & -0.02 & -0.42 & 0.675 \\
\hline & Frequency of contact at 9 months* & 0.09 & 0.07 & 0.05 & 1.25 & 0.213 \\
\hline
\end{tabular}

Note: *Natural log.

Abbreviations: $\mathrm{B}$, b-coefficient; $\mathrm{HbA}_{\mathrm{Ic}}$, hemoglobin $\mathrm{A}_{\mathrm{Ic}} ; P, P$-value; $\mathrm{SE} \mathrm{B}$, standard error of b-coefficient; $t, t$ statistic.

of a home telemonitoring program for patients with T2D. Within the telehealth literature, detail related to nursepatient interaction has not been collected in most studies, nor have clinical or utilization outcomes been examined over time, thereby decreasing the likelihood of further understanding the role that this technology might play in assisting in the self-management of individuals with T2D. Implications for practice for health care providers include training and familiarity with the use of technology to remotely monitor and interact with patients with T2D. Telemonitoring programs such as the one noted in the current study have produced a wide variety of interventions through a number of different modes of delivery. Variations in telemonitoring programs may have implications for how care is delivered and received as well as how processes and outcomes of care are measured. Examples of variations in the programs might include differences between the relationships that patients have with each of the nurses working with them through the program and responding to their questions, patients' comfort with the home monitoring process and feasibility of monitoring on a daily basis, all of which may have individual effects on study results. These variations, in addition to those patient-level variables such as diet, exercise, medication regimen, and comorbid

Table 5 Outcomes of care: sensitivity regressions with frequency of contact predicting DBP levels controlling for age, months enrolled, and DBP levels 3 months prior

\begin{tabular}{|c|c|c|c|c|c|c|}
\hline Dependent variable & Independent variable & B & SE B & $\beta$ & $t$ & $P$ \\
\hline \multirow[t]{5}{*}{ DBP at 6 months } & Constant & 23.65 & 5.67 & & 4.17 & 0.001 \\
\hline & DBP at 3 months & 0.71 & 0.05 & 0.67 & 15.32 & 0.001 \\
\hline & Age (years) & -0.10 & 0.06 & -0.07 & -1.65 & 0.100 \\
\hline & Months enrolled & 0.00 & 0.00 & 0.02 & 0.48 & 0.631 \\
\hline & Frequency of contact at 3 months* & 1.19 & 0.71 & 0.07 & 1.67 & 0.095 \\
\hline \multirow[t]{5}{*}{ DBP at 9 months } & Constant & 34.69 & 6.33 & & 5.49 & 0.001 \\
\hline & DBP at 6 months & 0.60 & 0.05 & 0.60 & $1 \mathrm{I} .40$ & 0.001 \\
\hline & Age (years) & -0.06 & 0.07 & -0.05 & -0.99 & 0.326 \\
\hline & Months enrolled & 0.00 & 0.00 & -0.04 & -0.72 & 0.475 \\
\hline & Frequency of contact at 6 months* & 0.08 & 0.74 & 0.01 & 0.11 & 0.914 \\
\hline \multirow[t]{5}{*}{ DBP at 12 months } & Constant & 28.74 & 7.50 & & 3.83 & 0.001 \\
\hline & DBP at 9 months & 0.64 & 0.06 & 0.57 & 10.14 & 0.001 \\
\hline & Age (years) & -0.05 & 0.07 & -0.04 & -0.62 & 0.533 \\
\hline & Months enrolled & 0.00 & 0.00 & -0.12 & -2.20 & 0.029 \\
\hline & Frequency of contact at 9 months* & 1.28 & 0.75 & 0.10 & I.7I & 0.088 \\
\hline
\end{tabular}

Note: *Natural log.

Abbreviations: $\mathrm{B}$, b-coefficient; DBP, diastolic blood pressure; $P, P$-value; SE B, standard error of b-coefficient; $t, t$ statistic. 
Table 6 Outcomes of care: sensitivity regressions with frequency of contact predicting SBP levels controlling for age, months enrolled, and SBP levels 3 months prior

\begin{tabular}{|c|c|c|c|c|c|c|}
\hline Dependent variable & Independent variable & B & SE B & $\beta$ & $t$ & $\mathbf{P}$ \\
\hline \multirow[t]{5}{*}{ SBP at 6 months } & Constant & 24.78 & 7.68 & & 3.23 & 0.001 \\
\hline & SBP at 3 months & 0.76 & 0.05 & 0.72 & 16.97 & 0.001 \\
\hline & Age (years) & -0.05 & 0.08 & -0.03 & -0.61 & 0.540 \\
\hline & Months enrolled & 0.00 & 0.00 & 0.04 & 1.00 & 0.320 \\
\hline & Frequency of contact at 3 months* & 2.57 & 1.02 & 0.11 & 2.52 & 0.012 \\
\hline \multirow[t]{5}{*}{ SBP at 9 months } & Constant & 45.16 & 8.55 & & 5.28 & 0.001 \\
\hline & SBP at 6 months & 0.59 & 0.05 & 0.62 & 12.20 & 0.001 \\
\hline & Age (years) & 0.18 & 0.09 & 0.10 & 1.91 & 0.058 \\
\hline & Months enrolled & 0.00 & 0.00 & -0.06 & -1.21 & 0.227 \\
\hline & Frequency of contact at 6 months* & 0.16 & 1.06 & 0.01 & 0.15 & 0.880 \\
\hline \multirow[t]{5}{*}{ SBP at 12 months } & Constant & 23.88 & 8.88 & & 2.69 & 0.008 \\
\hline & SBP at 9 months & 0.81 & 0.05 & 0.74 & 15.77 & 0.001 \\
\hline & Age (years) & 0.01 & 0.10 & 0.01 & 0.14 & 0.890 \\
\hline & Months enrolled & 0.00 & 0.00 & -0.05 & -1.08 & 0.283 \\
\hline & Frequency of contact at 9 months* & 0.71 & 0.97 & 0.03 & 0.74 & 0.462 \\
\hline
\end{tabular}

Note: *Natural log.

Abbreviations: B, b-coefficient; $P, P$-value; SBP, systolic blood pressure; SE B, standard error of b-coefficient; $t, t$ statistic.

conditions that were previously noted, further compound how care is delivered, measured, and interpreted.

Within the current telemonitoring interventions for patients with $\mathrm{T} 2 \mathrm{D}$, a great variation exists in how $\mathrm{HbA}_{1 \mathrm{c}}, \mathrm{SBP}$, and DBP are measured as program outcomes. ${ }^{20,21}$ In this study, to determine if the frequency of contact would predict $\mathrm{HbA}_{1 \mathrm{c}}$ levels in the subsequent 3-month period, frequency of contact was lagged by 3 months. This approach to the examination

Table 7 Outcomes of care: results for mixed model regressions between frequency of contact and $\mathrm{HbA}_{\mathrm{Ic}}$, DBP, and SBP levels after controlling for months enrolled

\begin{tabular}{|c|c|c|c|c|c|}
\hline $\begin{array}{l}\text { Dependent } \\
\text { variable }\end{array}$ & $\begin{array}{l}\text { Independent } \\
\text { variable }\end{array}$ & Estimate & SE & $t$ & $P$ \\
\hline \multirow[t]{6}{*}{ Change in $\mathrm{HbA}_{\mathrm{Ic}}$} & Intercept & -0.75 & 0.07 & -11.27 & 0.001 \\
\hline & Baseline $\mathrm{HbA}_{\mathrm{Ic}}$ & 0.86 & 0.03 & 27.99 & 0.001 \\
\hline & Age & 0.00 & 0.01 & 0.42 & 0.673 \\
\hline & Months enrolled & -0.03 & 0.08 & -0.37 & 0.713 \\
\hline & Time & 0.45 & 0.06 & 7.30 & 0.001 \\
\hline & Frequency & 0.07 & 0.05 & 1.29 & 0.199 \\
\hline \multirow[t]{6}{*}{ Change in SBP } & Intercept & -3.21 & 0.87 & -3.70 & 0.001 \\
\hline & Baseline SBP & 0.65 & 0.03 & 21.80 & 0.001 \\
\hline & Age & -0.03 & 0.05 & -0.59 & 0.554 \\
\hline & Months enrolled & -0.13 & 0.89 & -0.14 & 0.885 \\
\hline & Time & 0.13 & 0.51 & 0.26 & 0.794 \\
\hline & Frequency & 0.90 & 0.61 & 1.49 & 0.136 \\
\hline \multirow[t]{6}{*}{ Change in DBP } & Intercept & -2.01 & 0.62 & -3.22 & 0.001 \\
\hline & Baseline DBP & 0.63 & 0.03 & 18.68 & 0.001 \\
\hline & Age & -0.01 & 0.04 & -0.22 & 0.825 \\
\hline & Months enrolled & -0.98 & 0.64 & -1.53 & 0.128 \\
\hline & Time & 0.19 & 0.36 & 0.53 & 0.595 \\
\hline & Frequency & 0.41 & 0.44 & 0.95 & 0.344 \\
\hline
\end{tabular}

Abbreviations: $\mathrm{DBP}$, diastolic blood pressure; $\mathrm{HbA}_{1}$, hemoglobin $\mathrm{A}_{1 \mathrm{l}} ; \mathrm{P}, \mathrm{P}$-value; $\mathrm{SBP}$, systolic blood pressure; $t, t$ statistic; $\mathrm{SE}$, standard error. of existing data allowed the researcher to examine the effects that telephonic outreach by a nurse would have on clinical outcomes of care in the subsequent 3 months. This unique approach to examination of the telemonitoring process of care and clinical outcomes of care measures for patients with T2D has not been implemented in previous research studies.

Further, the approach of categorization of change in $\mathrm{HbA}_{1 \mathrm{c}}$ between time periods, in relation to the frequency of contact in prior months, is novel and contributes to the limited literature on the relationship between the process of care and the outcomes of care. The consideration of whether contacts preceded or followed the change in $\mathrm{HbA}_{1 \mathrm{c}}$ was necessary in light of the secondary data that was utilized within this study. Essentially, being able to quantify outreach efforts between the nurse and the patient, and controlling for earlier $\mathrm{HbA}_{1 \mathrm{c}}$, allowed the researcher to consider that increased outreach effort was associated with those patients with poorer control or elevated $\mathrm{HbA}_{1 \mathrm{c}}$, while fewer outreach effort was associated with patients with better control or lower $\mathrm{HbA}_{1 \mathrm{c}}$ levels. While it was ultimately found that the frequency of contact had no predictive value of the improvement in $\mathrm{HbA}_{1 \mathrm{c}}$ levels, SBP, or DBP values, it remains important to examine the

Table 8 Outcomes of care: results for ANOVAs for frequency of contact by change in $\mathrm{HbA}_{\mathrm{lc}}$ levels

\begin{tabular}{llll}
\hline & $\boldsymbol{F}$ & df & $\boldsymbol{P}$ \\
\hline $\mathrm{HbA}_{\mathrm{Ic}}$ level 3-6 months & 1.74 & 4,565 & 0.139 \\
$\mathrm{HbA}_{\mathrm{Ic}}$ level 6-9 months & 2.69 & 4,448 & $0.03 \mathrm{I}$ \\
$\mathrm{HbA}_{\mathrm{Ic}}$ level 9-12 months & 3.49 & $4,43 \mathrm{I}$ & 0.008 \\
\hline
\end{tabular}

Abbreviations: ANOVAs, analysis of variances; $F, F$ statistic; $d f$, degrees of freedom; $\mathrm{HbA}_{\mathrm{Ic}}$, hemoglobin $\mathrm{A}_{\mathrm{Ic}} ; P, P$-value. 
Table 9 Outcomes of care: mean and SD for frequency of contact by change in $\mathrm{HbA}_{\mathrm{Ic}}$ levels

\begin{tabular}{|c|c|c|c|c|c|c|c|}
\hline Source & Change in $\mathrm{HbA}_{\mathrm{Ic}}$ & M & SD & $\mathbf{N}$ & Minimum & Maximum & Interquartile range \\
\hline Frequency of contact at 3 months/change & Increase & 2.95 & 0.99 & 16 & 0.00 & 4.80 & 0.80 \\
\hline \multirow[t]{4}{*}{ in $\mathrm{HbA}_{\mathrm{Ic}}$ from 3 to 6 months } & Decrease & 2.45 & 1.10 & 347 & 0.00 & 4.38 & 0.85 \\
\hline & No change-normal & 2.96 & 0.83 & 9 & 1.39 & 3.95 & 1.36 \\
\hline & No change-near normal & 2.53 & 1.17 & 30 & 0.00 & 4.29 & 1.01 \\
\hline & No change-poor & 2.90 & 0.83 & 168 & 0.00 & 4.84 & 0.78 \\
\hline Frequency of contact from 3 to 6 months/ & Increase** & 2.95 & 0.99 & 128 & 0.00 & 4.80 & 0.80 \\
\hline change in $\mathrm{HbA}_{\mathrm{Ic}}$ from 6 to 9 months & Decrease* & 2.45 & 1.10 & 204 & 0.00 & 4.38 & 0.85 \\
\hline \multicolumn{8}{|l|}{ Change in $\mathrm{HbA}_{\mathrm{Ic}}$ from 6 to 9 months } \\
\hline & No change-normal & 2.96 & 0.83 & 24 & 1.39 & 3.95 & 1.36 \\
\hline & No change-near normal & 2.53 & 1.17 & 24 & 0.00 & 4.29 & 1.01 \\
\hline & No change-poor** & 2.90 & 0.83 & 73 & 0.00 & 4.84 & 0.78 \\
\hline Frequency of contact from 6 to 9 months/ & Increase & 2.63 & 1.09 & 168 & 0.00 & 4.50 & 0.82 \\
\hline \multirow[t]{4}{*}{ change in $\mathrm{HbA}_{\mathrm{Ic}}$ from 9 to 12 months } & Decrease & 1.78 & 1.54 & 63 & 0.00 & 4.20 & 3.04 \\
\hline & No change-normal ${ }^{* * *}$ & 2.14 & 1.21 & 54 & 0.00 & 3.74 & 1.01 \\
\hline & No change-near normal & 2.54 & 1.23 & 41 & 0.00 & 4.63 & 1.23 \\
\hline & No change-poor**** & 2.51 & 1.22 & 110 & 0.00 & 4.85 & 0.94 \\
\hline
\end{tabular}

Notes: *Significantly lower mean score compared to no change-poor and increase; **significantly higher mean compared to decrease; ***significantly lower frequency of contact compared to no change-poor; $* * * *$ significantly higher frequency of contact compared to no change-normal.

Abbreviations: $\mathrm{HbA}_{\mathrm{Ic}}$, hemoglobin $\mathrm{A}_{\mathrm{Ic}} ; \mathrm{M}$, mean; $\mathrm{SD}$, standard deviation.

relationship between the variables to consider what, other than the frequency of contact, might have led to improved clinical outcomes.

Participants with a decrease in $\mathrm{HbA}_{1 \mathrm{c}}$ over the 3-month time period had significantly lower frequency of contact compared with those who had no change-poor control or increase in $\mathrm{HbA}_{1 \mathrm{c}}$. This may be interpreted to mean that those patients with consistently poor control, as evidenced by an $\mathrm{HbA}_{1 \mathrm{c}}$ of greater than $8 \%$, required and received additional outreach from, or to, a nurse to manage their condition. Those patients who had $\mathrm{HbA}_{1 \mathrm{c}}$ in the normal range of $7 \%-8 \%$ would perhaps have required less frequent contact with a nurse and so did not receive or make contact regarding their condition. This finding is consistent with literature regarding those patients who struggle to control their diabetes require more education and assistance to improve their $\mathrm{HbA}_{1 \mathrm{c}}$ levels. 22,23

Another noteworthy finding was that within the sample, as age increased, $\mathrm{HbA}_{1 \mathrm{c}}$ tended to decrease. Although prevalence of T2D increase with age, it is not clear from the literature if age positively predicts $\mathrm{HbA}_{1 \mathrm{c}}$ levels. ${ }^{24}$ It may be that management of this chronic, progressive disease, as reflected in $\mathrm{HbA}_{1 \mathrm{c}}$ levels, is more strongly linked to years living with the disease, than with age of the individual with the disease. Since the sample data did not include years living with diabetes, it is not possible to conclude that this is the case in the present study.

Similarly important was the finding that as age increases, SBP tended to increase while DBP decreased. Findings from the National Health and Nutrition Examination Survey (NHANES) IV 1999-2000 $(\mathrm{n}=5,448)$ indicated that uncontrolled hypertension prevalence increased with advancing age, tended to be higher in women, and highest among nonHispanic Blacks. ${ }^{25}$ However, NHANES IV did not specify a relationship between age and systolic or diastolic hypertension. The American Heart Association, based on results from the Framingham Study, suggests that SBP is a better marker for cardiovascular disease (CVD) than DBP because DBP typically increases until age 50, then levels off until age 60 and remains stable or decreases thereafter. ${ }^{26}$ SBP has been shown to rise steadily with age as a result of increased incidence of cardiac and vascular disease.

In the current study, females tended to have lower DBP levels than males. The Centers for Disease Control and Prevention indicates that reducing DBP from 90 to $80 \mathrm{mmHg}$ in both men and women with diabetes reduces the risk of major cardiovascular events by $50 \%{ }^{1} \mathrm{SBP}$ is a better marker than DBP for increased risk of CVD, but in the present study, elevated DBP was an indicator of poor blood pressure control. This may contribute to the sample's overall tendency toward hypertension, which is consistent with having T2D.

Finally, while elevated SBP baseline levels were not significantly related to sex, it is important to consider how elevated baseline DBP levels may have contributed toward hypertension in the current sample of patients with T2D. The majority of the study sample (66\%) comprised women, all of whom have T2D, placing them at greater risk of CVD 
and coronary heart disease (CHD) than males with T2D and women without T2D. ${ }^{27}$ This finding is significant in light of more recent studies that have suggested that there is a relative risk increase for acute myocardial infarction with diabetes that is higher in women than in men. ${ }^{28,29}$ Ultimately, the current sample of patients with confirmed T2D, the majority of whom were females and who exhibited elevated baseline blood pressure levels, were those most in need of appropriate preventative strategies such as outreach by the telemonitoring nurse.

\section{Limitations}

A limitation of the secondary data analysis design is the lack of full control inherent in true experimental designs. Since there were no randomization or comparison groups, and no option of controlling independent variables, rival hypotheses may arise that compete with the manipulation of the treatment as an explanation for observed or desired results. ${ }^{30}$ The difficulty of examining the impact of nurse-patient contacts with an observational design is that there is uncertainty surrounding the conclusions reached. Essentially, the design did not allow for true in-depth examination of what, other than the volume of contacts occurring, was actually being exchanged during those contacts. It would be helpful to understand whether contacts were nurse-initiated versus patient-initiated and the types of questions or concerns, other than the nurse responding to alerts, may have prompted the contact. Having access to the detail of the contacts that occurred may have allowed for more robust answers to the research questions and further exploration of why changes in clinical outcomes were occurring. While this data was collected by the nurse when responding to a patient alert, the analysis of this large volume of information was outside the scope of this study.

A unique approach was undertaken to evaluate the effects of frequency of contact on the clinical outcomes, in the absence of more robust data to evaluate the relationship between contact and $\mathrm{HbA}_{1 \mathrm{c}}$, SBP, and DBP. These results address an area of opportunity that has been frequently cited in terms of telehealth initiatives for patients with T2D, which is the need for more detailed evaluation of different frequencies and durations of interventions. ${ }^{21,31,32}$ In a systematic review of telehealth intervention on glycemic control and adherence, the authors examined 14 studies in which patients received phone calls from nurses to assist in the management of blood glucose, diet, physical activity, and medication adherence. Due to considerable differences between study processes and study outcomes, the authors were unable to make strong conclusions about the effectiveness of the interventions. However, the authors noted that to optimize the effect of telehealth for T2D, careful examination of various dosages and durations of interventions is required. ${ }^{31}$ Similarly, a systematic review of home telehealth interventions for diabetes management was conducted and, after review of 26 studies, the authors found it was not clear what clinical services, in what quantities were delivered by the interventions. The authors ultimately concluded that due to wide variations in the design and quality of the telehealth interventions, more studies were required to give more accurate insights into the clinical effectiveness. ${ }^{21}$

Another significant limitation was the lack of patientlevel data that may have contributed to the individual's status. Patients were on medications throughout enrollment in the program, however, this information was not accessible to the researcher. Patients may have had adjustments made to their medications while being monitored but this information was noted in the Notes section of the data collection system of the telemonitoring program, which was not accessible to the researcher. Similarly, physician office visits were not provided to the researcher, making it impossible to determine if changes in treatment regimen were made, resulting in an increase or decrease in nurse contacts. When patients had episodic illnesses as well as existing comorbid conditions, it was documented in the Notes section of the data collection system that was not available to the researcher due to the inability to de-identify the data. Similarly, diet, activity levels, and body mass index, commonly examined in relation to management of $\mathrm{T} 2 \mathrm{D}$, was not easily accessible within the telemonitoring program data collection system. All the noted patient-level data inputs that were not available to the researcher may have, individually or collectively, had significant impacts on the clinical outcomes noted within the study.

The findings from the current study necessitate enhancements to the research design in future studies of telemonitoring programs for patients with T2D. To extend the generalizability of the findings beyond the patients from this specific telemonitoring program, the structure, process, and outcomes of care in the telemonitoring environment should be examined in a larger sample of patients that includes adequate representation of ethnic minority populations. Despite the variations that exist in the design of telemonitoring programs, detailed documentation of the structural aspects, the process measures of care delivered, as well as the outcome measures attained need to be further 
examined to draw more consistent conclusions about the effectiveness of care delivery within this alternative environment.

\section{Acknowledgment}

The authors would like to acknowledge Dr Dunn, Ann Frisch, and Susan Lehrer for their invaluable support in this research.

\section{Disclosure}

The authors report no conflicts of interest in this work.

\section{References}

1. Centers for Disease Control and Prevention. Diabetes Report Card 2014. Atlanta, GA: Centers for Disease Control and Prevention, US Department of Health and Human Services; 2014.

2. Sigurdardottir A. Self-care in diabetes: model of factors affecting selfcare. J Clin Nurs. 2005;14:301-314.

3. Diabetes Complications and Control Trial Research Group. The effect of intensive therapy for diabetes on the development and progression of long-term complications. N Eng J Med. 1993;329:977-986.

4. Norris SL, Engelgau MM, Narayan KM. Effectiveness of self-management training in T2D: a systematic review of randomized controlled trials. Diabetes Care. 2001;24(3):561-587.

5. Bonds DE, Goff DC, Karter AJ, Saad M, Selby JV, Zaccaro DJ. Ethnic and racial differences in diabetes care: the Insulin Resistance Atherosclerosis Study. Diabetes Care. 2003;26:1040-1046.

6. Gary TL, McGuire M, McCauley J, Brancati FL. Racial comparisons of health care and glycemic control for African American and white diabetic adults in an urban managed care organization. Dis Manag. 2004;25-34

7. Heisler M, Smith DM, Hatward RA, Krein SL, Kerr EA. Racial disparities in diabetes care processes, outcomes, and treatment intensity. Med Care. 2003;4:1221-1232.

8. Karter AJ, Ferrara A, Liu JY, Moffett HH, Ackerson LM, Selby JV. Ethnic disparities in diabetic complications in an insured population. JAMA. 2002;287:2519-2527.

9. Norris SL, Glasgow RE, Engelgau MM, O'Connor PJ, McCulloch D. Chronic disease management: a definition and systematic approach to component interventions. Dis Manage Health Outcomes. 2003;11(8):477-488.

10. Dansky KH, Bowles KH, Palmer L. Clinical outcomes of telehomecare for diabetic patients receiving home care. J Inf Tech Healthc. 2003;1: $61-74$.

11. Gardner SE, Frantz RA, Pringle-Sprecht, JK. How accurate are chronic wound assessments using interactive video technology? J Gerontol Nurs. 2001;27(1):15-20.

12. Jenkins RL, McSweeney M. Assessing elderly patients with congestive heart failure via in-home interactive communication. J Gerontol Nurs. 2001;27:21-27.
13. Phillips VL, Vesmarovich S, Hauber R, Wiggers E, Egner A. Telehealth: reaching out to newly injured spinal cord patients. Public Health Rep. 2001;116:94-102.

14. Stricklin ML. Home talk/healthy talk: improving patients' health status with telephone technology. Home Healthc Nurse. 2000;18:53-61.

15. Garcia-Lizana F, Sarria-Santamera A. New technologies for chronic disease management and control: a systematic review. J Telemed Telecare. 2007;13:63-68.

16. Bensink M, Hailey D, Wootton R. A systematic review of success and failures in home telehealth: preliminary results. $J$ Telemed Telecare. 2006;12:8-16.

17. Donabedian A. Evaluating the quality of medical care. Millbank Mem Fund Q. 1966;44(1):166-203.

18. Donabedian A. The quality of care: how can it be assessed? JAMA. 1988;23(30):1743-1748.

19. Gustafson DH, Hundt AS. Findings of innovation research applied to quality management principles for health care. Health Care Manage Rev. 1995;20(2):16-33.

20. Farmer A, Gibson OJ, Tarassenko L, Neil A. A systematic review of telemedicine interventions to support blood glucose self-monitoring in diabetes. Diabetic Med. 2005;22:1372-1378.

21. Polisena J, Tran K, Cimon K, Hutton B, McGill S, Palmer K. Home telehealth for diabetes management: a systematic review and metaanalysis. Diabetes Obes Metab. 2009;11:913-930.

22. Norris SL, Lau J, Smith SJ, Schmid CH, Engelgau MM. Self-management education for adults with T2D: a meta-analysis of the effect on glycemic control. Diabetes Care. 2002;25(7):1159-1172.

23. Peek ME, Cargill A, Huang ES. Diabetes health disparities: a systematic review of health care interventions. Med Care Res Rev. 2007; 64(5):101S-156S.

24. Hashimoto Y, Futamura A, Ikushima M. Effect of aging on $\mathrm{HbA}_{1 \mathrm{c}}$ in a working male Japanese population. Diabetes Care. 1995;18: $1337-1340$

25. Hajjar I, Kotchen T. Trends in prevalence, awareness, treatment, and control of hypertension in the United States, 1988-2000. JAMA. 2003; 290(2):199-206.

26. Franklin SS, Gustin W, Wong ND, et al. Hemodynamic patterns of age-related changes in blood pressure. The Framingham Heart Study. Circulation. 1997;96:308-315.

27. Lee C, Joseph L, Colosimo A, Dasgupta K. Mortality in diabetes compared with previous cardiovascular disease: a gender-specific meta-analysis. Diabetes Metab. 2012;38:420-427.

28. Pilote L, Dasgupta K, Guru V, et al. A comprehensive view of sex-specific issues related to cardiovascular disease. CMAJ. 2007;176:S1-S44.

29. Yusuf S, Hawkins S, Ounpuu S, et al. Effect of potentially modifiable risk factors associated with myocardial infarction in 52 countries (the INTERHEART study): case-control study. Lancet. 2004;364:937-952.

30. Polit DF, Beck CT. Nursing Research: Principles and Methods. Philadelphia: Lippincott Williams \& Wilkins; 2004.

31. Cassimatis M, Kavanagh DJ. Effects of type 2 diabetes behavioural telehealth interventions on glycaemic control and adherence: a systematic review. J Telemed Telecare. 2012;18:447-450.

32. Wooton R. Twenty years of telemedicine in chronic disease managementan evidence synthesis. $J$ Telemed Telecare. 2012;18:211-220.
Patient Related Outcome Measures

\section{Publish your work in this journal}

Patient Related Outcome Measures is an international, peer-reviewed, open access journal focusing on treatment outcomes specifically relevant to patients. All aspects of patient care are addressed within the journal and practitioners from all disciplines are invited to submit their work as well as healthcare researchers and patient support groups.

\section{Dovepress}

The manuscript management system is completely online and includes a very quick and fair peer-review system. Visit http://www.dovepress. com/testimonials.php to read real quotes from published authors. 